\title{
Monitoring Konektivitas Internet Dengan Load Balancing Menggunakan Metode Equal Cost Multi Path Pada SMK Yadika 12 Depok
}

\author{
Toni Sukendar ${ }^{1}$, Mohammad Ikhsan Saputro ${ }^{2}$ \\ Universitas Bina Sarana Informatika, Universitas Mohammad Husni Thamrin \\ Toni.tns@bsi.ac.id
}

\begin{abstract}
ABSTRAK
Kebutuhan akses internet untuk mencari informasi dan komunikasi dari hari ke hari semakin meningkat. Saat ini SMK Yadika 12 Depok menggunakan dua koneksi dari penyedia layanan internet yang berbeda untuk menjaga agar proses belajar mengajar dapat tetap berjalan dengan baik. Namun, pemanfaatan kedua koneksi Internet tersebut belum seimbang dan metode pengalihan jalur koneksi yang mengalami kendala masih dilakukan secara manual sehingga membutuhkan waktu yang cukup lama untuk proses pengalihan jalur tersebut. Oleh karena itu, tujuan penelitian ini adalah menerapkan teknik load balancing) dengan router mikrotik menggunakan metode Equal Cost Multi Path. Hasil pengujian menunjukkan jaringan kedua Lab SMK Yadika 12 Depok menjadi satu jaringan yang sama dan memiliki dua sumber access internet. Acces internet yang dilakukan oleh client akan dibebankan ke kedua ISP yang ada. Beban bandwith sudah ada pembatasan per client menjadi 512k pada saat mengunduh dan dan mengunggah file.
\end{abstract}

Kata kunci : ECMP, load balancing, mikrotik

\section{ABSTRACT}

The need for internet access to find information and communication from day to day is increasing. At present SMK Yadika 12 Depok uses two connections from different internet service providers to keep the teaching and learning process going well. However, the utilization of the two internet connections has not been balanced and the method of diverting the connection path that is experiencing problems is still done manually so that it takes a long time for the process of switching the line. Therefore, the purpose of this study is to apply load balancing techniques with a proxy router using the Equal Cost Multi Path method. The test results show that the networks of the two Labs of SMK Yadika 12 Depok become the same network and have two internet access sources. Internet access conducted by the client will be charged to the two existing ISPs. There is already a bandwidth burden per client to 512k when downloading and uploading files.

Keywords : ECMP, load balancing, proxy, mikrotik

\section{PENDAHULUAN .}

Sumber belajar memiliki peranan penting dalam menentukan proses belajar agar pembelajaran menjadi efektif dan efisien dalam pencapaian tujuan. Perkembangan teknologi jaringan Internet telah mengubah paradigma dalam mendapatkan mendapatkan informasi yang dibutuhkan dimanapun dan kapanpun waktu yang diinginkan(Setiyani, 2010). Guru dan siswa mulai memanfaatkan internet sebagai sumber untuk mencari informasi, artikel maupun pengetahuan baru ketika proses pembelajaran sedang http://ejournal.urindo.ac.id/index.php/TI berlangsung di kelas maupun di luar kelas. Sekolahsekolah baik di perkotaan dan pedesaan telah mengintegrasikan jaringan Internet ke dalam proses belajar agar siswa dengan mudah mencari materi dan memahami pelajaran. Berdasarkan data dari Badan Pusat Statistik pada tahun 2018, sekolah yang telah menggunakan fasilitas internet dalam proses belajar sebanyak 76,25\%(Tri \& Atika, 2018).

Kebutuhan akses internet untuk mencari informasi dan komunikasi dari hari ke hari semakin meningkat. Saat ini SMK Yadika 12 Depok menggunakan dua koneksi dari penyedia jasa layanan internet yang 
berbeda untuk menjaga agar proses belajar mengajar dapat tetap berjalan dengan baik. Namun, pemanfaatan kedua koneksi Internet tersebut belum seimbang dan metode pengalihan jalur koneksi yang mengalami kendala masih dilakukan secara manual sehingga membutuhkan waktu yang cukup lama untuk proses pengalihan jalur tersebut(Khasanah \& Utami, 2018).

Ketika banyak permintaan dari pengguna ke suatu server maka server tersebut akan terbebani karena harus melakukan proses pelayanan terhadap permintaan pengguna. Oleh karena itu, perlu dilakukan proses pendistribusian beban trafik berbasiskan jaringan pada dua atau lebih jalur koneksi secara seimbang. Beberapa penelitian sebelumnya telah menerapkan teknik load balancing menggunakan metode Per Connection Classfier (Oktivasari \& Sanjaya, 2015) (Utami et al., 2017), Nth (Sukendar, 2017), dan Equal Cost Multi Path (Husni et al., 2018) (Anwar \& Nurhaida, 2019). Berdasarkan uraian di atas, solusi untuk mengatasi pemasalahan yang terjadi pada SMK Yadika 12 Depok adalah menerapkan teknik load balancing dengan Equal Cost Multi Path (ECMP). Load balancing dengan metode ECMP ini akan membagi beban trafik pada dua jalur gateway secara beraturan dengan beban yang sama (equal cost) sehingga meningkatkan throughput, mengurangi response time dan menghindari penumpukan trafik yang berlebihan (Husni et al., 2018).

\section{METODE.}

Sesuai dengan permasalahan yang telah dikemukakan sebelumnya, maka jenis penelitian ini adalah penelitian eksperimen. Penelitian ini berawal dari pengamatan tentang akses jaringan internet di SMK Yadika 12 Depok.

Berdasarkan hasil pengamatan, pengelola jaringan internet sekolah mengalami kesulitan dalam menggabungkan dan membagi beban bandwith dari dua provider yang digunakan di SMK Yadika 12 Depok. Solusi dari permasalahan ini adalah menerapkan metode ECMP dalam sistem load and balancing. Sistem load and balancing ini berbasis router mikrotik yang dapat diakses oleh pengelola jaringan internet sekolah sehingga dapat melakukan penggabungan dan pembagian bandwith secara seimbang sehingga trafik dapat berjalan optimal, memaksimalkan throughput, memperkecil waktu tanggap dan menghindari overload pada salah satu jalur koneksi

\section{Pengumpulan Data}

Objek penelitian ini adalah mengabungkan dua ISP yang berbeda. Dalam melakukan pengumpulan data untuk mendukung penelitian ini diperoleh dari beberapa sumber diantaranya adalah:

a. Data Primer

Data yang diperoleh secara langsung dari sumber, misalnya data-data hasil wawancara dan diskusi langsung dengan pengelola jaringan dan pengamatan langsung pada jaringan LAN SMK Yadika 12 Depok.

b. Data sekunder

Data yang diambil dari jurnal dan buku penelitian sebelumnya tentang penerapan load balacing.

Teknik pengumpulan data yang dilakukan dalam tugas akhir ini, sebagai berikut :

1. Observasi

Observasi dilakukan dengan mengumpulkan data secara langsung terhadap penggunaan jaringan internet di SMK Yadika 12 Depok.

2. Wawancara

Wawancara dilakukan kepada pengelola jaringan untuk memperoleh informasi lebih mendalam terkait jaringan internet.

3. Studi Pustaka

Studi pustaka dilakukan dengan mengumpulkan dan mempelajari literatur yang berkaitan dengan pemecahan masalah mengenai penggabungan dua atau lebih sumber internet dari ISP yang berbeda. Sumber literatur berupa buku teks, karya ilmiah, dan situs-situs penunjang. Kegunaan metode ini diharapkan dapat mempertegas teori serta keperluan analisis dan mendapatkan data yang sesungguhnya.

2. Metodologi Perancangan Jaringan Komputer Perancangan jaringan komputer yang digunakan pada tugas akhir ini menggunakan pendekatan PPDIOO (Irawan, 2015) yang terbagi menjadi beberapa tahapan, sebagai berikut:

a. Fase Persiapan

Menentukan kebutuhan jaringan internet dan strategi jaringan yang akan digunakan. 
b. Fase Perencanaan

Melakukan identifikasi kebutuhan jaringan sesuai dengan karakter dan penilaian yang telah dilakukan.

c. Fase Desain

Mendesain topologi jaringan dengan memperhatikan ketersediaan, kehandalan, keamanan, skalabilitas, dan kinerja.

d. Fase Implementasi

Melakukan instalasi dan konfigurasi perangkat jaringan sesuai dengan desain, tanpa merubah jaringan yang sudah ada sebelumnya.

e. Fase Operational

Melakukan pengelolaan jaringan seperti, monitoring, maintenance, serta upgrade perangkat sesuai dengan kebutuhan.

f. Fase Optimal.

Mengidentifikasikan masalah serta menyelesaikannya sebelum masalah tersebut mempengaruhi kinerja dari sebuah jaringan.

\section{HASIL DAN PEMBAHASAN}

1. Analisa Jaringan

Jaringan LAN yang ada di SMK Yadika 12 Depok diperuntukan kepada manajemen, guru, dan staff. Sedangkan untuk siswa, akses internet diperoleh dari laboratorium Teknik Komputer Jaringan (TKJ) dan multimedia serta access point yang terdapat di sekolah tersebut. Analisa yang penulis lakukan tentang LAN pada SMK Yadika 12 Depok.

2. Blok Jaringan

Sistem jaringan komputer yang ada di SMK Yadika 12 Depok secara umum menggunakan topologi star. Koneksi dengan internet bersumber dari dua Internet Service Provider (ISP) yang digunakan untuk akses internet laboratorium TKJ dan Mutimedia. Blok jaringan Local area Network (LAN) pada SMK Yadika 12 Depok.

http://ejournal.urindo.ac.id/index.php/TI

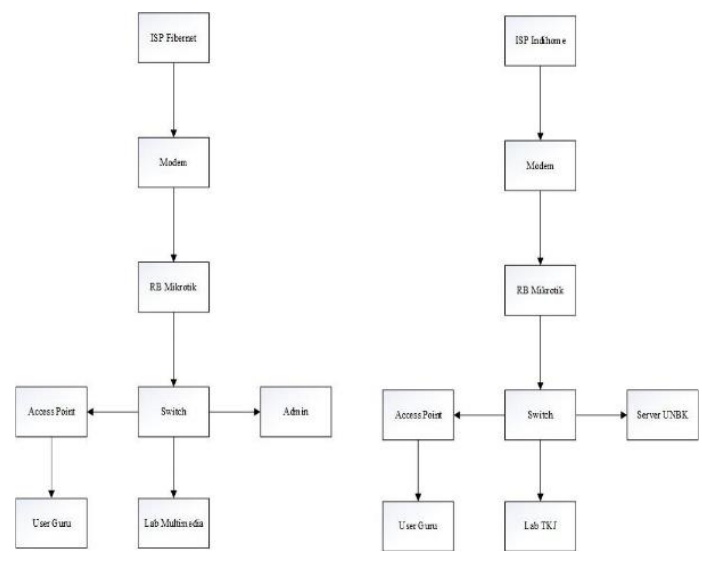

Gambar 1.. Blok Jaringan SMK Yadika 12 Depok

Adapun penjelasan dari blok jaringan pada SMK

Yadika 12 Depok sebagai berikut:

1. SMK Yadika 12 Depok memiliki 2 jaringan terpisah yaitu jaringan yang ada di laboratorium TKJ dan Multimedia yang memiliki sumber access internet masingmasing.

2. Terdapat 2 ISP (internet service provider) pada jaringan SMK Yadika 12 Depok yaitu Fibernet dan Indihome (telkomsel) yang masing-masing memiliki Bandwith sebesar 20 dan 50 mbps.

3. Menggunakan dua buah router yang berfungsi sebagai penghubung ISP (internet service provider) dengan switch dan access point. Router yang digunakan adalah jenis RB941.

4. Menggunakan dua buah modem adsl yang berfungsi sebagai penghubung ISP (internet service provider) dengan perangkat router. Modem adsl yang digunakan adalah jenis ZTE zxhn 6609 yang memiliki 4 buah port Ethernet.

5. Pada masing- masing jaringan terdapat 1buah switch, yang dijadikan switch pusat berfungsi sebagai penghubung antara router dengan PC (Personal Computer) admin, Access point dan PC (Personal Computer) client yang terdapat di laboratorium TKJ dan Multimedia SMK Yadika 12 Depok. Switch yang digunakan adalah tipe TL-SF1048 yang memiliki 48 port.

6. Dua buah wireless access point yang 
berfungsi untuk menghubungkan client yang terhubung melalui media wireless dengan jaringan SMK Yadika 12 Depok. Adapun wirelesss access point yang digunakan adalah TP-LINK TD-W8151N.

7. Satu buah server yang berfungsi hanya sebagai server UNBK.

8. Client yang berfugsi sebagai pengguna layanan jaringan SMK Yadika 12 Depok. Adapun client yang terhubung ke dalam jaringan adalah:

a. 20 buah PC (Personal Computer) yang berada di lab TKJ terhubung melalui media transmisi kabel (LAN).

b. 20 buah PC (Personal Computer) yang berada di lab Multimedia terhubung melalui media transmisi kabel (LAN).

c. 1 buah $\mathrm{PC}$ admin yang terhubung kedalam jaringan melalui media transmisi kabel (LAN).

9. Media transmisi yang digunakan pada jaringan SMK Yadika 12 Depok adalah kabel LAN cat $5 \mathrm{e}$ dengan konektor RJ45.

\section{Skema Jaringan}

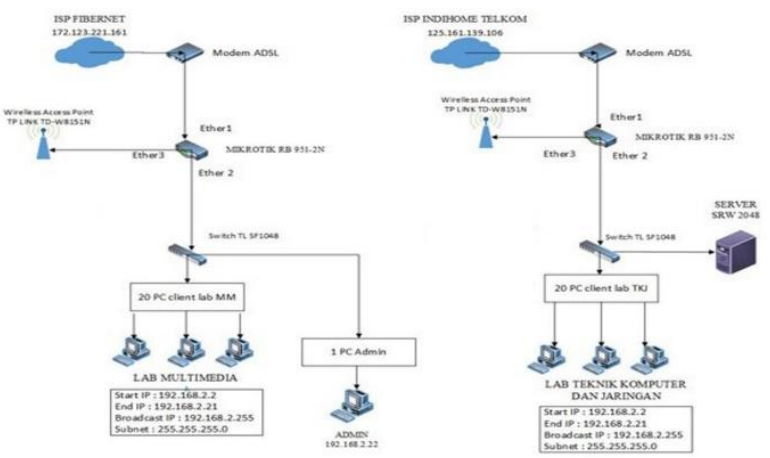

Gambar 2. Skema jaringan SMK Yadika 12 Depok

SMK Yadika 12 Depok memiliki dua buah jaringan LAN yaitu jaringan LAN untuk lab Multimedia dan jaringan lab TKJ. Masing-masing dari jaringan LAN tersebut memiliki sumber akses internet yang berbeda. ISP yang digunakan adalah telkomsel (Indihome) dan Fibernet. Jaringan lab TKJ dan Multimedia memiliki IP Address kelas C dengan subnet prefix 24. Client yang terhubung melalui wireless ruang guru akan diarahkan ke dalam jaringan lab Multimedia, sedangkan client yang terhubung melalui wireless siswa akan diarahkan ke dalam jaringan lab TKJ.

Tabel 1. Daftar IP Addreess

\begin{tabular}{|c|c|c|c|}
\hline No & Perangkat Keras & IP Address & Subnet \\
\hline 1 & Router RB951 & & \\
& (Lab Multimedia) & 172.123 .221 .161 & - \\
& IP Public & 192.168 .2 .1 & 255.255 .255 .0 \\
& Ether 1 & 192.168 .3 .1 & 255.255 .255 .0 \\
& Ether 2 & & \\
\hline 2 & Router & & - \\
& RB951 & 125.161 .139 .106 & 255.255 .255 .0 \\
& (Lab TKJ) & 192.168 .2 .1 & 255.255 .255 .0 \\
& IP Public & 192.168 .3 .1 & \\
& Ether 1 & & .0 \\
\hline 3 & Ether 2 & & .0 \\
\hline 4 & PC Admin & 192.168 .2 .22 & 255.255 .255 \\
& PC user lab & $192.168 .2 .2-$ & 255.255 .255 \\
& Multimedia & 192.168 .2 .21 & .0 \\
\hline 5 & PC user lab TKJ & $192.168 .2 .2-$ & 255.255 .255 \\
& & 192.168 .2 .21 & .0 \\
\hline 6 & User wireless & $192.168 .3 .2-$ & 255.255 .255 \\
& access point & 192.168 .254 & .0 \\
& ruang & & \\
\hline 7 & guru & & 255.255 .255 \\
& User wireless & $192.168 .3 .2-$ & .0 \\
& access point & 192.168 .254 & \\
& siswa & & \\
\hline
\end{tabular}

IP Address yang digunakan di jaringan SMK Yadika 12 Depok adalah IPv4 kelas C dengan subnet mask default 255.255.255.0. IP Address user dikedua laboratorium didapatkan secara manual sedangkan user yang terhubung melalui wireless acces point didapat secara DHCP.

1. Skema Usulan Agar dapat menjalankan metode EQUAL COST MULTI PATH dengan baik maka sebaiknya skema jaringan Local Area Network (LAN) pada SMK Yadika 12 Depok di rubah menjadi. 


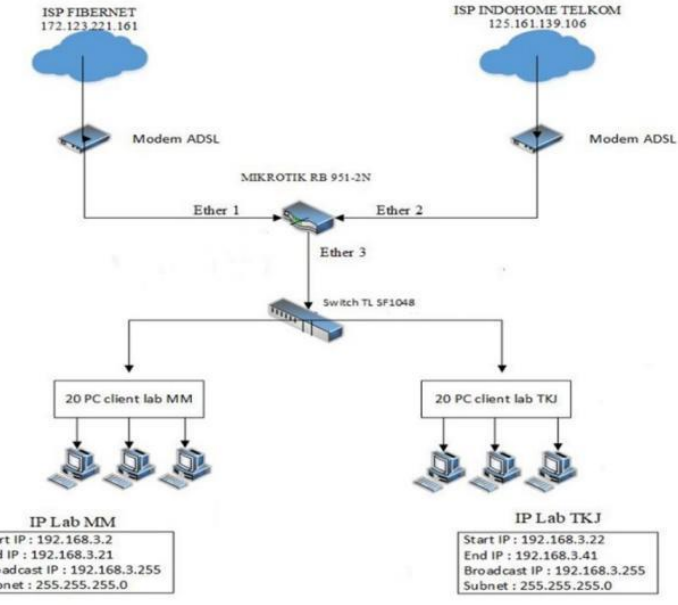

Gambar 3. Skema Jaringan Usulan.

Dari gambar diatas, penulis mengusulkan adanya penggabungan koneksi akses internet dari kedua lab TKJ dan Multimedia dengan cara load balance untuk mendapatkan traffic data yang lebih baik dan internet yang stabil. Karena sering terjadi kendala akses internet pada lab apabila koneksi salah satu ISP down atau terlalu banyak yang mengakses pada salah satu ISP.

1. Konfigurasi Usulan

Adapun IP Address jaringan usulan pada SMK Yadika 12 Depok adalah sebagai berikut

Tabel 2. IP Address usulan

\begin{tabular}{|c|c|c|c|}
\hline No & Perangkat & IP address & Subnet \\
\hline 1. & $\begin{array}{l}\text { Router RB941 IP } \\
\text { Public Ether } 1 \\
\text { Ether } 2\end{array}$ & $\begin{array}{l}8.100 .1 \\
192.168 .150 .1\end{array}$ & $\begin{array}{l}255.255 .255 .0 \\
255.255 .255 .0 \\
255.255 .255 .0\end{array}$ \\
\hline 2. & User Lab & $\begin{array}{l}192.168 .3 .2- \\
192.168 .3 .41\end{array}$ & $255 . .255 .255 .0$ \\
\hline 3. & $\begin{array}{l}\text { User wireless } \\
\text { access point } \\
\text { ruang guru }\end{array}$ & $\begin{array}{l}192.168 .4 .2- \\
192168.4 .52\end{array}$ & 255.255 .255 .0 \\
\hline 4. & $\begin{array}{l}\text { User } \\
\text { wirele } \\
\text { ss access point } \\
\text { siswa }\end{array}$ & $\begin{array}{l}192.168 .3 .43- \\
192.168 .3 .254\end{array}$ & 255.255 .255 .0 \\
\hline 5. & PC Admin & 192.168.3.42 & 255.255 .255 .0 \\
\hline
\end{tabular}

Berikut ini adalah tahapan simulasi konfigurasi load balancing ECMP dengan menggunakan winbox :

1. Konfirasi load balancing dengan metode ECMP.

a. Buka winbox lalu login, dari Mikrotik Winbox. Kemudian kita akan menambahkan satu rule firewall nat untuk koneksi ISP FIBERNET agar client mendapat akses internet dari jalur FIBERNET. Caranya klik menu "IP $>$ firewall $>$ pilih tab NAT $>$ klik simbol $(+)>$ lalu isikan perintah ini chain $=$ srcnat, out-interface $=$ FIBERNET, action = masquerade". Untuk yang kedua agar client mendapat akses internet dari jalur INDIHOME. Caranya klik menu "IP $>$ firewall $>$ pilih tab NAT $>$ klik simbol $(+)>$ lalu isikan perintah ini chain $=$ srcnat, out- interface $=$ INDIHOME, action $=$ masquerade"

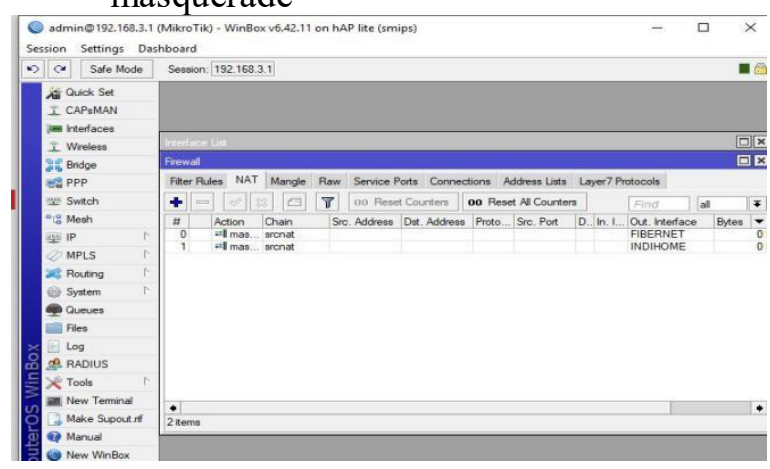

Gambar 4. Menu Firewall NAT

b. Selanjutnya masing-masing NAT Rule, isi chain dengan srcnat dan out- interface dengan untuk menentukan jalur yang akan digunakan untuk internet.

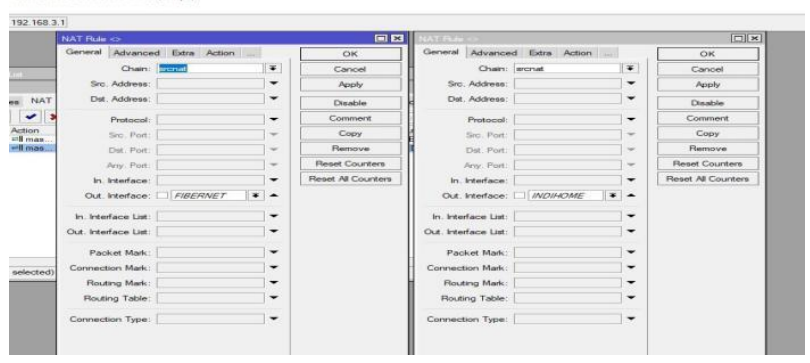

Gambar 5. Menu Rule Firewall NAT

c. Selanjutnya, isi action dengan masquerade untuk mengubah ip private menjadi ip public. Setelah selesai klik Apply, lalu OK. 


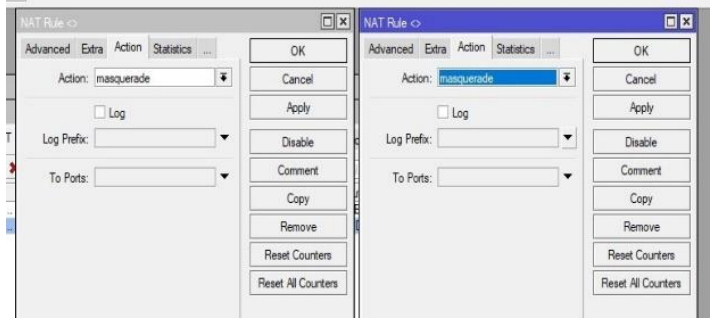

Gambar 6. Menu Firewall NAT ( action )

d. Selanjutnya, klik menu "IP > Routes > klik tombol (+) " untuk konfigurasi load balancing ECMP. Caranya menambahkan rule default gateway dengan dst-address $=$ 0.0.0.0 dan gateway = FIBERNET, INDIHOME.

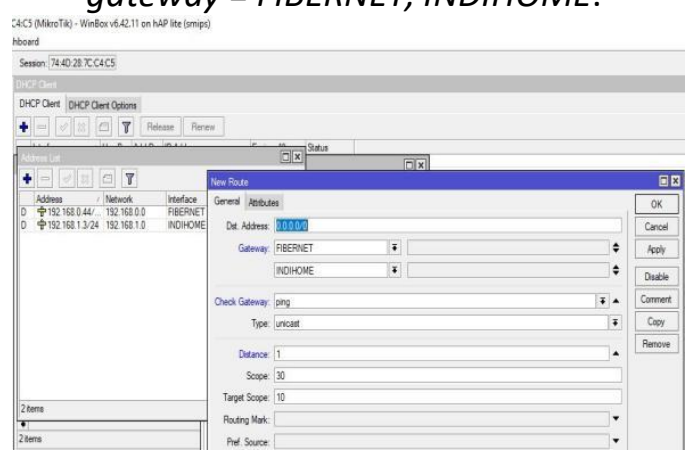

Gambar 7. Form Route

2. Hasil Pengujian

Sesudah diterapkannya teknik load balancing, jaringan kedua Lab SMK Yadika 12 Depok menjadi satu jarigan yang sama dan memiliki dua sumber access internet. Acces internet yang dilakukan oleh client akan dibebankan ke kedua ISP yang ada. Beban bandwith sudah ada pembatasan per client menjadi $512 \mathrm{k}$ pada download dan upload.

\section{KEIMPULAN DAN SARAN}

KESIMPULAN

Berdasarkan analisa jaringan Local Area Network (LAN) Pada SMK Yadika 12 Depok yang telah penulis lakukan. Maka penulis dapat menyimpulkan diantaranya :

Menggabungkan jaringan kedua lab dan koneksi kedua ISP secara load balance menggunakan metode ECMP pada jaringan SMK yadika 12 Depok dengan pembagian beban trafik pada jalur koneksi antara trafik menuju domain lokal dan internasional sehingga trafik dapat berjalan optimal dan menghindari overload pada salah satu jaringan. Jika salah satu link jaringan internet terputus, maka seluruh beban akan dialihkan secara otomatis ke jaringan internet yang masih aktif.

\section{SARAN}

Berdasarkan analisa yang telah dilakukan, penulis mengajukan beberapa saran untuk pengembangan lebih lanjut dari penelitian yang telah dilakukan, antara lain:

Pengaturan authentikasi login dengan metode user profile masih dapat dikembangkan lagi. Seperti menggunakan batasan waktu (limited access time) untuk guru,staff dan siswa saat mengakses jaringan wireless. Sehingga tidak setiap saat atau waktu dapet terkoneksi ke dalam jaringan, yang juga dapat meminimalisir pemakaian bandwith yang besar.

\section{DAFTAR PUSTAKA}

[1]. Anwar, M. K., \& Nurhaida, I. (2019). Implementasi Load Balancing Menggunakan Metode Equal Cost Multi Path (ECMP) Pada Interkoneksi Jaringan. Jurnal TelekomunikasiDan Komputer,9(1),39. https://doi.org/10.22441/incomtech.v9i1.5003

[2\}. Arlis, S. (2019). Analisis Firewall Demilitarized Zone Dan Switch Port Security Pada Jaringan. 29-39.

[3]. Assidik, A. (2015). Perancangan Jaringan Lan dan WLAN Berbasis Mikrotik Di SMKN 1 Muntok. Jurnal SIFOM, 02(September), 4-8.

[4]. Darmawan, D., \& Marlinda, L. (2015). Implementasi Jaringan Wireless Outdoor Menggunakan Nanobridge. Teknik Komputer Jaringan, I(2), 253-259.

[5]. Firdaus, M. I. (2017). Analisis Perbandingan Kinerja Load Balancing Metode Ecmp (Equal Cost Multi-Path) Dengan Metode Pcc (Per Connection Classifier) Pada Mikrotik Routeros Technologia: Jurnal Ilmiah, 8(3), 165.

https://doi.org/10.31602/tji.v8i3.1139

[6]. Handono, F. W. (2016). Kajian Ip Virtual ( Virtual Server ) Terhadap Keamanan Jaringan. Paradigma, XVIII(1), 21-27.

https://ejournal.bsi.ac.id/ejurnal/index.php/paradi 
gma/article/view/871

[7]. Haqqi, M., \& Badrul, M. (2016). Segmentasi Jaringan Dengan Menggunakan Virtual Local Area Network (Study Kasus PT. Jalur Nugraha Ekakurir). Teknik Komputer AMIK BSI, II No.2(2), 8 .

[8]. Hatika, L. K., Budiyono, A., \& Almaarif, A. (2019). Analisis Ketepatan Deteksi Malware Pada Software Antivirus Menggunakan Metode Analisis Statis Accuracy Analysis of Malware Detection in Antivirus Software. 6(2), 7812- 7819.

[9]. Husni, A., Budiman, E., Taruk, M., \& Setyadi, H. J. (2018). Teknik Load Balancing Menggunakan Metode Equal Cost Multi Path ( Ecmp ) Untuk Mengukur Beban Traffic Di Diskominfo Tenggarong. Prosiding Seminar Ilmu Komputer Dan Teknologi Informasi, 3(1), 103-109.

[10]. Irawan, B. (2015). Pengembangan laboratorium komputer terpadu universitas esa unggul dengan metode ppdioo. 11 number.

[11]. Khasanah, S. N., \& Utami, L. A. (2018). Implementasi Failover Pada Jaringan WAN Berbasis VPN. Jurnal Teknik Informatika STMIK Antar Bangsa, IV(1), 62-66.

[12]. MADCOM. (2015). Panduan lengkap membangun sendiri system jaringan. C.V ANDI OFFSET.

[13]. Martias, \& Djuanda, R. F. (2018). Pembatasan Jumlah Client Menggunakan Security MAC- Address with Cisco. Transistor EI (Jurnal Elektro Dan Informatika) UNISSULA, $3(3)$.

[14]. Maulana, Y. I., Studi, P., \& Informatika, M. (2017). Perancangan Perangkat Lunak Sistem Informasi Pendataan Guru Dan Sekolah (SINDARU) Pada Dinas Pendidikan Kota Tangerang Selatan. Jurnal Pilar Nusa Mandiri, 13(1), 21-27.

[15]. Muzawi, R. (2018). Pengaturan Bandwidth dan QoS Pada PC Router Menggunakan Kernel Gnu / Linux dan FreeBSD. Jurnal Edik Informatika, 2(Januari), 80-82. https://doi.org/10.13140/RG.2.2.10700.92809
[16]. Oktapiani, R. (2017). Penerapan Metode Forward Chaining Pada Sistem Pakar Kerusakan Komputer. Klik, 04(02), 136-145.

[17]. Oktivasari, P., \& Sanjaya, R. (2015). Implementasi Sistem Load Balancing Dua ISP Menggunakan Mikrotik dengan Metode Per Connection Classfier. Multinetics, 1(2), 33. https://doi.org/10.32722/vol1.no2.2015.pp33-37

[18]. Pamuji, S. A., Iswahyudi, C., \& Informatika, T. (2017). Jurnal JARKOM Vol . 5 No . 1 Desember 2017 ISSN: 2338-6304 Jurnal JARKOM Vol . 5 No . 1 Desember 2017 ISSN: 2338-6304. 5(1), 65-75.

[19]. Rahadjeng, I. R., \& Puspitasari, R. (2018). Analisis Jaringan Local Area Network (LAN) Pada PT. MUSTIKA Ratu TBK Jakarta Timur. Prosisko, 5(1), 53-60.

[20]. Setiyani, R. (2010). Pemanfaatan Internet Sebagai Sumber Belajar. Dinamika Pendidikan, 5(2), 117-133. https://doi.org/10.15294/dp.v5i2.4921 Sitanggang, R. (2019). 729-Article Text-2577-1-1020190628. 4(1).

[21]. Sukendar, T. (2017). Keseimbangan Bandwidth Dengan Menggunakan Dua ISP Melalui Metode Nth Load Balancing Berbasiskan Mikrotik. Jurnal Teknik Komputer Amik Bsi, III(1), 86-92.

[22]. Supendar, H. (2016). PENERAPAN LINUX ZENTYAL SEBAGAI FILTERING DAN BANDWIDTH MANAGEMENT PADA JARINGAN PT . ANTA CITRA ARGES. JURNAL TEKNIK KOMPUTER AMIK BSI, II(24), 22-30.

[23]. Tri, S., \& Atika, N. H. (2018). Penggunaan dan Pemanfaatan Teknologi Informasi dan Komunikasi (P2TIK) Sektor Pendidikan 2018 (M. Wardhini, E. Sari, \& Z. Ilmiyah (eds.)). Badan Pusat Statistik.

[24]. Utami, F., Lindawati, \& Suzanzefi. (2017). Optimalisasi Load Balancing Dua Isp Untuk Manajemen Bandwidth Berbasis Mikrotik. Prosiding Seminar Nasional Multi Disiplin Ilmu \& Call For Paperiding SNATI F, 4, 451-457. 
[25]. Zakaria, A., Prihantara, A., \& Hartono, A. A. (2019). Integrasi Application Programing Interface, PHP, dan MySQL untuk Otomatisasi Verifikasi dan Aktifasi Pengguna Layanan Hotspot MikroTik. JUITA: Jurnal Informatika, 7(2), 63. 
